Розроблено математичну модель для оперативного оцінювання абсолютного значення тиску та його градієнта на зовнішній поверхні компонування конус-ицліндр під час його обтікання трансзвуковим потоком. Надано можливість визначення параметрів трансзвукової зони польоту через коефічієнт енергооснащеності. Застосовано коефічієнт динамічності для визначення тиску на поверхні аеродинамічного компонування. Дано практичні рекомендації щодо вибору місць установлення дренажного устаткування

Ключові слова: коефічієнт енергооснащеності, коефічієнт динамічності, градієнт тиску, трансзвукова зона, дренажні пристрої

口-

Разработана математическая модель для оперативной оценки абсолютного значения давления $и$ его градиента на внешней поверхности компоновки конус-иилиндр при её обтекании трансзвуковым потоком. Представлена возможность определения параметров трансзвуковой зоны полёта через коэффициент энерговооружённости. Применён коэффициент динамичности по определению давления на поверхности аэродинамической компоновки. Даны практические рекомендации относительно выбора мест установки дренажного оборудования

Ключевые слова: коэффициент әнерговооружённости, коэффициент динамичности, градиент давления, трансзвуковая зона, дренажные устройства

\section{DEVELOPMENT AND APPLICATION OF THE METHOD FOR POSITIONING DRAINAGE DEVICES IN THE HEAD FAIRING}

S. Dav y d o v

Doctor of Technical Sciences, Professor Department of Design and Constructions Oles Honchar Dnipro National University Gagarina ave., 72, Dnipro, Ukraine, 49010

P. S e m e n e n k o Engineer

Yuzhnoye SDO

Kryvorizka str., 3, Dnipro, Ukraine, 49010 E-mail: semenenko1981@mail.ua

\section{Introduction}

At present, it is impossible to determine pressure distribution over the surface of an aerodynamic assembly without performing ballistic calculations and knowledge of a certain aerodynamic configuration. The flight trajectory sections in which the zone of transonic flow around the carrier rocket (CR) takes place are determined by ballistic calculations as well and aerodynamic calculations determine realization of the modes of flow over the assembly. In this (classical) way, aerodynamic loads acting on the assembly along the whole path of the CR flight are determined. However, in the case of sketch and pre-design work, a necessity arises to estimate maximum possible pressure fluctuations for choosing an optimal assembly and solving the issues of drainage of the spacecraft (SC) placement zones.

Medium pressure on the outer surface of the head fairing (HF) affects the pressure in the SC zone. Being the part of the drainage system, drainage devices (DD) in the HF provide the necessary level of ventilation for the SC zone. Moreover, DD are also necessary to meet requirements concerning excessive pressure before the moment of the HF throw-off. In addition, the pressure gradient under the HF during the CR flight in atmosphere has predetermined limitations as well. Excess of these levels can disrupt performance of SC or the elements of its design [1]. First studies of gas escape from unsealed compartments of space-rocket systems have appeared in 1970 [1]. This work describes the nuances to be taken into account in designing SC and the compartment in which it stays during the atmospheric phase of the CR flight.

A change in pressure values is characterized by a gradient. A need to study not only the value of absolute pressure on the external surface of $\mathrm{HF}$ and under it but also the pressure gradients appears. There is a phase with the greatest fluctuations in external pressure on the HF surface during the CR flight in the Earth's atmosphere. This special flight phase is characterized by the range of Mach numbers $0.8 \leq M \leq 1.2$. The transonic flight phase features the highest possible level of sharp pressure drops [2-4].

Various methods for calculating pressure on the external fairing surface are available in periodical scientific publications. Part of them deal with the study of dependence of internal pressure (inside the fairing) on the external pressure. Finding these pressures as well as their mutual influences in various variations determine solution of a particular problem. Methods of a rapid assessment of reaction of a leaky CR compartment on the fast external pressure drops are presented in [5]. Work [6] studies effectiveness of drainage devices in the interrelations of internal and external pressures. Article [7] sets forth a mathematical model for calculating the process of leaky vessel drainage as a function of the CR flight time. Work [8] presents calculation of excess pressure in leaky CR compartments and the numerical and analytical methods specifically developed to this end. Solution to the problem of drainage of leaky hydraulically connected vessels at subsonic and supersonic velocities of CR flight is given in [9]. 
As it follows from analysis of the presented scientific works, the problems of determining external and internal pressures in leaky containers are well studied. However, the literature does not fully cover all issues of this engineering issue. For example, methods for transient processes, in particular for the transonic phase of the CR flight have been poorly developed. There are no engineering analytical methods for determining the pressure values for which there is no need in ballistic calculations. There are no methods based on the use of dimensionless quantities as basic parameters.

Development of a mathematical model and a method enabling analytical search for the best DD locations in the HF is a focal problem. It is necessary for taking into account the effect of maximum external pressure variations on the HF and minimization of this effect on the pressure inside the HF. This study stage was devoted to working out a mathematical model for calculating the pressure and its gradient on the surface of the aerodynamic assembly. This model will ensure an operational determination of DD locations minimizing depressurization rate.

\section{Literature review and problem statement}

The need to take into account effect of depressurization rate or the rate of air intake into the HF room where the SC is placed arose during practical operation and development of both SC and CR. In the course of SC and CR improvement, problems of various kinds appeared that might unexpectedly arise during operation of new HF designs or SC operation in error conditions. They include the problems associated with a sharp change in pressure under the HF during atmospheric flight phase, a small volume of HF and a tight spacecraft placement under the HF $[10,11]$. Works devoted to the study of drainage of HF, SC and the system of HF and SC are actualized periodically. Methods of solving both general and specific issues related to drainage of dry CR compartments were proposed. In all cases, the atmospheric CR flight phase or a part of it is considered.

Work [12] gives an example of how during operation of the Zenit CR (Ukraine), peculiarities of flow over a cone-cylinder assembly manifested themselves at a transonic velocity by appearance of overpressure under the fairing. Detailed analysis of peculiarities of the jumping pressure variation on the cone-cylinder assembly and studies in the assembly design have enabled normalization of the drainage process.

Issues of drainage of small space volumes under the fairing along the entire flight path are considered in [13]. With the help of numerical Runge-Kutta method, pressure is determined by the CR flight time. Maximum pressure fluctuations on the HF are determined by calculation. Dependence of the consumption characteristics of the DD on the CR flight time is pointed out. Application of numerical methods that require use of computers can be considered as disadvantage of this method, that is, the method is not adapted to the design (search) works.

An analytical technique for determining internal pressure of drained compartments is given in [14]. It is stated there that the maximum pressure change is often the most important parameter that affects depressurization. However, it is noted that application of this technique for complex external transients is limited. From the authors' point of view, the fact that this technique assumes existence of completed ballistic calculations can be considered its dis- advantage since it operates with quantities that depend on the flight time.

In [15], details of an experiment with modeling depressurization of the SpaceX Dragon Trunk CR compartment are given. The experiment in a vacuum chamber was recognized as the best way to ensure safety of the payload. It was noted that the critical phase of depressurization occurs when the pressure drops from $760 \mathrm{~mm} \mathrm{Hg}$ to the vacuum of space. It is stated that the most critical period occurs in the transonic flight zone. It was noted that ballistic calculations are required to determine altitudes of transonic zones. Absence of operational methods for obtaining sought altitudes to be used in analysis of predicted results can be attributed to the promising type of works. Such preliminary results could be helpful in a preliminary selection of compressors for experimenting.

It was shown in [16] that numerical determination of the moments of maximum loading of the carrier rocket HF in determination of its shape to reduce number and longevity of expensive experiments is a topical question. The cases of maximum aerodynamic resistance were determined at a Mach number of 1.2. It was noted that a controlled random search method was applied to obtain required geometric parameters of the HF. Application of analytical methods taking into account the force of aerodynamic resistance allows preliminary work to be done for reducing the number of calculations using modern numerical methods.

The paper [17] presents development of a new analytical model that can predict the maximum pressure change on the walls of a spacecraft or the HF. The method uses nonlinear one-dimensional equations for isentropic flow of an ideal gas. Availability of computation machinery for its application and dependence on the trajectory parameters of the CR can be considered a disadvantage of this method.

The issues of air escape from internal spacecraft volumes to the subfairing space are considered in [18] taking into account differential pressure on the outer surface of the HF. The authors investigated dependence of the ventilation elements at small differential pressures and the features of their action under conditions of depressurization. At the same time, the question of maximum external pressure was actualized since internal pressure is its function.

The problems of drainage of volumes in a vehicle descending into the dense atmospheric layers are solved in [19]. The solutions developed for the Titan IV CR (USA) on its atmospheric flight phase are used in this work. In fact, work [19] considers the inverse problem. The solved issues remained the same: ensuring the predicted process of draining dry compartments and searching for peak pressure values.

The paper [20] presents the results of the works intended for ensuring reduction of the rate of pressure drop in the area of the spacecraft onboard the Dnepr CR. The disadvantage is that the article considered the options based solely on the drainage system modernization, in particular, variations of the trajectory parameters while the launch altitude of the $\mathrm{CR}$ were not considered.

As it is pointed out in [21], one of the lines of studies touched the technical risks in launching the Dnepr CR associated with the HF design, in particular, designing of a drainage system (DS). The work identified the risks associated with designing of the space vehicle head, namely, one of them is drainage on the atmospheric flight phase. The article states that the selected drainage scheme made it possible to reduce level of the maximum pressure drop to $25 \%$. 
In [22], studies of transient gas-dynamical processes are described for an outflow from vessels with substantiation of application of the mathematical models used in this case and taking into account influence of various real factors.

\section{The study objective and tasks}

This work objective was to develop an engineering method for determining pressure on the outer surface of the cone-cylinder assembly when the carrier rocket passes transonic flight phase without the need in ballistic calculations to determine the best locations for placement of drainage devices.

To achieve this goal, the following tasks were accomplished:

- analysis of the traditional presentation of pressure on the outer surface of the cone-cylinder assembly and presentation of this pressure in a new form;

- analysis of variables on which each component of quasi-static pressure depends and development of a mathematical model;

- comparison of theoretical results and experimental data, determination of conditions for minimizing the pressure gradient under the head fairing and elaboration of practical recommendations

\section{Definition of pressure and its dependence on} dimensional and dimensionless quantities

The results of experimental studies of absolute pressure on the surface of the aerodynamic assembly performed in laboratory conditions are usually presented [23] in the form

$$
C_{P}=\left(P-P_{\infty}\right) / q_{\infty}
$$

where $C_{P}$ is the dimensionless pressure coefficient; $P$ is the measured absolute value of pressure on the external surface of the assembly; $P_{\infty}$ is the pressure in an undisturbed flow; $q_{\infty}$ is velocity head in an undisturbed flow.

The pressure acting at the surface of the aerodynamic assembly is determined by formula (1) and is traditionally represented as two summands:

$$
P=P_{\infty}+0.5 C_{P} \rho_{\infty} V_{\infty}^{2},
$$

where $\rho_{\infty}$ is the density of the incoming air in an undisturbed flow; $V_{\infty}$ is air velocity in an undisturbed flow.

The law of variation of the first summand (2) has the form [24]:

$$
\begin{aligned}
& P_{\infty}(h)=P_{0} e^{-\beta h}, \\
& \mathrm{~d} P_{\infty} / \mathrm{d} h=-P_{0} \beta e^{-\beta h},
\end{aligned}
$$

where $P_{0}=101,3 k$; $\mathrm{Pa}$ is the value of the sea level pressure; $\mathrm{h}, \mathrm{km}$ is altitude above the sea level; $\beta=0.13 \mathrm{~km}^{-1}$ is the altitude pressure gradient.

Analysis of expression (2) showed that it includes both dynamic components of pressure and kinematic parameters of the CR which leads to impossibility of solving it without preliminary ballistic calculations.
To this end, represent (2) in a new form:

$$
P=P_{\infty}\left(1+0.5 k C_{P} M_{\infty}^{2}\right),
$$

where $M_{\infty}$ is the Mach number in an undisturbed flow; $k$ is the adiabatic exponent for air.

Feature of (5) is that it has two multipliers but not two summands. The second multiplier depends on the dimensionless components and actually represents the dynamic factor in the form:

$$
C_{D}=1+0,5 k C_{P} M_{\infty}^{2} \text {. }
$$

Determination of the dynamic factor through the dimensionless coefficients does not require ballistic calculations.

\section{1. Mathematical modeling of a simplified definition} of the transonic carrier rocket flight

Along the trajectory of the CR flight, atmospheric pressure changes in a not abrupt way and is a function of altitude, therefore it was characterized in this work as a quasi-static component, $P_{\mathrm{Q}-\mathrm{S}}$.

Altitude definition for a quasi-static pressure is written as:

$$
h(t)=h_{S}+h_{V}(t)+\Delta h_{\text {Temp }}(t)
$$

where $h_{S}$ is the CR launch altitude; $h_{V}$ is altitude (length) of the vertical flight section; $\Delta h_{\text {Temp }}$ is the altitude of the CR flight section at which its pitch turn takes place.

The length of the vertical section of the CR flight and the section at which it changes its pitch is determined by its ballistic parameters [25-27]. One of the main factors is the power-to-weight ratio which is the ratio of the engine's empty thrust to the CR mass. It is called $v_{0}$ in the methodology. The power-to-weight ratio is the ratio of the engine thrust to the mass of the CR at the moment of its detachment from the launch table and is called the starting power-to-weight ratio, $v_{s}$. At the same time, an approximate relationship $v_{\mathrm{S}}=0.9 v_{0}$ is introduced. For the present-day carrier rockets, this coefficient varies in the range $1.2 \leq v_{S} \leq 2.1$.

Besides, it is necessary to take into account the temperature coefficient which depends on the ambient temperature at the CR start time. The method of its recording is given in [26]. Its linear approximation is proposed in the form:

$$
\Delta h_{\text {Temp }}(T)=\left\{\begin{array}{ll}
\left\{\begin{array}{ll}
-\frac{0.6}{55}\left[15^{\circ}-T\right] & -40^{\circ} \leq T \leq 15^{\circ} \\
\frac{0.3}{35}\left[T-15^{\circ}\right] & 15^{\circ} \leq T \leq 50^{\circ}
\end{array}\right\} v_{S}=2.1 \\
\left\{\begin{array}{ll}
-\frac{1.3}{55}\left[15^{\circ}-T\right] & -40^{\circ} \leq T \leq 15^{\circ} \\
\frac{0.8}{35}\left[T-15^{\circ}\right] & 15^{\circ} \leq T \leq 50^{\circ}
\end{array}\right\} v_{S}=1.2
\end{array}\right\} .
$$

To determine the dimensionless quasi-static pressure, express current atmospheric pressure in an undisturbed flow thru reduced atmospheric pressure and then express (3) and (4) in the form:

$$
P_{R}(h)=P_{\infty}(h) / P_{S V}=e^{-\beta h},
$$

where $P_{S V}=P_{0} e^{-\beta\left(h_{S}+h_{V}+\Delta h_{\text {Tenp }}(T)\right)}$ is the coefficient of reduction. 
Proceeding from (9), the atmospheric pressure gradient takes the form:

$$
\mathrm{d} P_{R}(h) / \mathrm{d} h=-\beta e^{-\beta h} .
$$

Introduce initial conditions to calculate the CR flight altitude at which its pitch change takes place: the altitude of the turn beginning is considered equal to zero, the program pitch angle is $\alpha=90^{\circ}$ [25], velocities and accelerations of the CR:

$$
h_{\text {Turn }}(0)=0, \quad d h_{\text {Turn }}(0) / d t=V_{V}, \quad d^{2} h_{R}(0) / d t=W_{V},
$$

where $V_{V}$ and $W_{V}$ are relative velocity and acceleration at a $h_{S}+h_{V}$ altitude for air temperature during launching equal to $+15^{\circ} \mathrm{C}$.

Acceleration of the $\mathrm{CR}$ at the beginning of vertical flight section is generally defined as described in [27]:

$$
W_{V}(0)=g\left(v_{V}-\sin \alpha-\bar{X}\right)
$$

where $g=9.81 \mathrm{~m} / \mathrm{s}$ is acceleration of gravity; $v_{V}$ is the value of power-to-weight ratio at a $h_{S}+h_{V}$ altitude; $a$ is the program pitch angle; $\bar{X}$ is the drag force reduced to the CR mass.

For simplification of expression (12), trajectories of the $\mathrm{CR}$ with various power-to-weight ratios were analyzed. This made it possible to establish that the value of the $\mathrm{CR}$ velocity at the end of the vertical flight section is $V_{V}<60 \mathrm{~m} / \mathrm{s}$. Therefore, within the accepted assumptions of this mathematical model, neglect the drag force, then (12) takes the form:

$$
W_{V}(0)=g\left(v_{V}-1\right),
$$

where $v_{B}$ is the value of the power-to-weight ratio at the $h_{S}+h_{V}$ altitude.

Express equation of the CR flight at which its pitch turn occurs in a form of a quadratic dependence expressed by the following formula:

$$
h_{\text {Turn }}\left(t, v_{S}\right)=V_{V}\left(v_{S}\right) t+0.5 W_{V}\left(v_{S}\right) t^{2},
$$

where $V_{V}$ and $W_{V}$ are quantities that depend on the starting power-to-weight ratio.

The found values of initial velocity and acceleration determine the beginning and the end of the transonic zone at the vertical section of the CR flight. They were chosen from the conditions obtained by means of formula (14) and the data from [26, 27].

The criterion of matching is the time at which the $\mathrm{CR}$ reaches the beginning and the end of the transonic zone. The calculated velocities and accelerations are presented in Table 1.

Table 1

Velocities and accelerations of a hypothetical CR for two extreme values of the power-to-weight ratio

\begin{tabular}{|c|c|c|}
\hline$v_{S}$ & $V_{V}, \mathrm{~km} / \mathrm{s}$ & $W_{V}, \mathrm{~km} / \mathrm{s}^{2}$ \\
\hline 1.2 & 0.04 & 0.00334 \\
\hline 2.1 & 0.0207 & 0.01152 \\
\hline
\end{tabular}

The developed mathematical model of movement of a hypothetical CR determines transonic altitudes with an accuracy of $1 \%$. Comparison was made with the calculated data obtained by ballistic calculations of various CR.
By substituting (14) into (9) and (10), dependences of the dimensionless quasi-static pressure and its time gradient were obtained:

$$
\begin{aligned}
& P_{Q-S}^{*}(t)=P_{\infty} / P_{S V}=e^{-\beta\left(V_{V}\left(v_{S}\right) t+0,5 W_{V}\left(v_{S}\right) t^{2}\right)}, \\
& P_{Q-S}^{*} / d t=P_{\infty} / P_{S V}=-\beta e^{-\beta\left(V_{V}\left(v_{S}\right) t+0,5 W_{V}\left(v_{S}\right) t^{2}\right)} .
\end{aligned}
$$

From a physical point of view, $P_{\mathrm{SV}}(9)$ is the static distribution of atmospheric pressure over altitude. The dimensionless quasi-static pressure $P_{Q-S}^{*}$ determines local pressure values near the outer surface of the $C R$ while being a function of time and the dependence of the velocity and acceleration of the $C R$. The latter are determined by the $C R$ starting power-to-weight ratio.

Investigate dependence of the $C R$ velocity on the flight altitude in the form of a polynomial:

$$
V(h)=V_{\mathrm{V}}+b_{1} h+b_{2} h^{2}
$$

where $V_{V}$ is the $C R$ velocity at the $h_{S}+h_{V}$ altitude; $b_{1}, b_{2}$ are the coefficients of the quadratic equation determined proceeding from the following conditions: at an altitude of $h_{0.8}$, the CR reaches velocity of $0.8 a$ and $1.2 a$ at an altitude $h_{1.2}$ where $a$ is the velocity of sound.

Coefficients for (17) taking into account Table 1 are given in Table 2.

Table 2

Initial velocity and coefficients of the quadratic equation polynomial for two extreme values of the power-to-weight ratio

\begin{tabular}{|c|c|c|c|}
\hline \multirow{2}{*}{$v_{S}$} & Initial velocity & \multicolumn{2}{|c|}{$\begin{array}{c}\text { Coefficients of } \\
\text { quadratic equation }\end{array}$} \\
\cline { 2 - 4 } & $V_{V}$ & $b_{1}$ & $b_{2}$ \\
\hline 1.2 & 0.04 & 0.03485 & -0.00057 \\
\hline 2.1 & 0.0207 & 0.012 & -0.0898 \\
\hline
\end{tabular}

Transform dependences (14) and (17) and obtain a quadratic dependence expressing the altitude of flight as a function of the Mach number in the form:

$$
h\left(M, v_{S}\right)=d_{1}\left(v_{S}\right) M+d_{2}\left(v_{S}\right) M^{2} .
$$

Coefficients of equation (18) are given in Table 3.

Coefficients of quadratic dependence for two extreme values of the power-to-weight ratio

\begin{tabular}{|c|c|c|}
\hline \multirow{2}{*}{$v_{S}$} & \multicolumn{2}{|c|}{ Coefficients of quadratic equation } \\
\cline { 2 - 3 } & $d_{1}$ & $d_{2}$ \\
\hline 1.2 & 5.62 & 3.11 \\
\hline 2.1 & 1.5 & 2.2 \\
\hline
\end{tabular}

Substitution of (18) into (9) and (10) has given dimensionless values of the quasi-static pressure component and its gradient as a function of the Mach number and the powerto-weight ratio (Fig. 1) at an ambient start temperature of $+15{ }^{\circ} \mathrm{C}$.

To obtain intermediate values, linear interpolation between the data shown in Fig. 1 is allowed. 


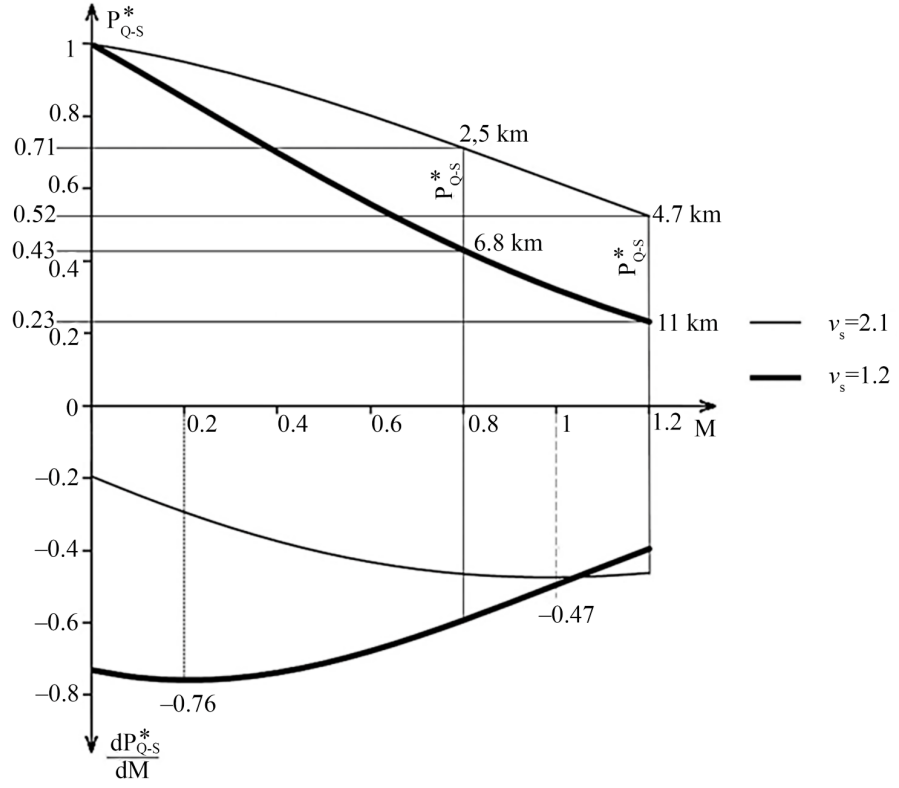

Fig. 1. Dependence of the dimensionless quasistatic pressure and its gradient on the Mach number

\section{2. Determination of the dependence of pressure} through the dynamic factor

The dynamic factor, like the pressure coefficient, is a function of three variables: the taper angle, the longitudinal coordinate of the assembly and the Mach number. The results of measuring absolute pressure on the external surface of the Dnepr CR for dimensionless coordinates are given in $[28,29]$. The dimensionless coordinates are determined by a ratio of distance from the top of the cylinder to the studied point $\mathrm{X}$ related to the $\mathrm{CR}$ diameter $\mathrm{d}$.

Fig. 2, $a$ shows distribution of pressure at the transonic section of the CR flight with coordinates $\bar{X}_{c y l}=0.03$ and $\bar{X}_{c y l}=1.7$. on the cylindrical surface. Fig. $2, b$ shows the pressure coefficient calculated by formula (2) and the dynamic factor calculated by formula (6)
By numerical differentiation of the pressure and dynamic coefficients by the Mach number, the values of their gradients for the same longitudinal coordinates are determined.

\section{Analysis of results and verification of the developed method for transonic} flight velocity

5. 1. Analysis of the results of determining transonic zone parameters

Increment in the value of the quasi-static component at $\mathrm{T}=-40{ }^{\circ} \mathrm{C}$ as compared with $T=+50{ }^{\circ} \mathrm{C}$ reaches $28 \%$ for $v_{S}=1.2$ and $12 \%$ for $v_{S}=2.1$.

Generalized parameters of the transonic zone for two power-to-weight ratios under study are presented in Table 4.

Table 4

Generalized parameters of the transonic zone for two extreme power-to-weight ratios

\begin{tabular}{|c|c|c|}
\hline \multirow{2}{*}{$\begin{array}{c}\text { Transonic zone } \\
\text { parameters }\end{array}$} & \multicolumn{2}{|c|}{$\mathrm{v}_{s}$} \\
\cline { 2 - 3 } & 1.2 & 2.1 \\
\hline Beginning, $\mathrm{km}$ & $5.8 \leq h \leq 6.8$ & $2.2 \leq h \leq 2.5$ \\
\hline End, km & $11 \leq h \leq 12.1$ & $4.7 \leq h \leq 5.5$ \\
\hline Length, km & $4.2 \leq \Delta h \leq 6.3$ & $2.3 \leq \Delta h \leq 3.3$ \\
\hline Time of transit, $\mathrm{s}$ & $15 \leq t \leq 22$ & $6 \leq t \leq 8$ \\
\hline Velocity of transit, $\mathrm{m} / \mathrm{s}$ & $224 \leq V \leq 377$ & $238 \leq V \leq 408$ \\
\hline
\end{tabular}

Dependence was determined for the pressure which at the beginning of the transonic flight zone for $v_{S}=2.11 .65$ times exceeds the pressure for $v_{S}=1.2$, at the end of the transonic zone becomes 2.26 times higher
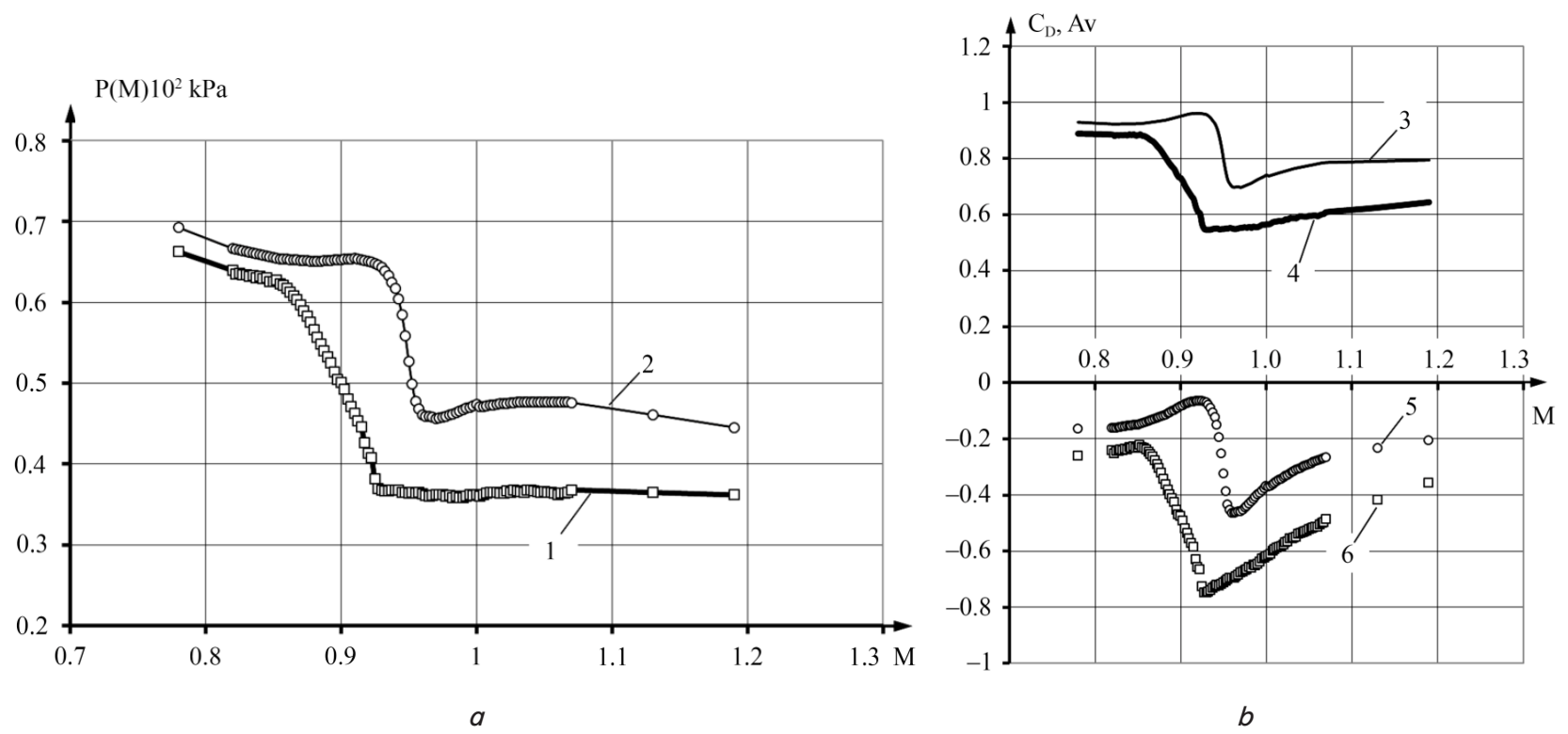

Fig. 2. Dependence of pressure on the Mach number and dependence of the pressure coefficient and the dynamic coefficient on the Mach number: 1, 2 are telemetric data of the absolute pressure change $(a) ; 3,4$ are dependences of the dynamic coefficient and 5.6 are dependences of the pressure coefficient $(b)$ 
5. 2. Analysis of the results of calculations for the dynamic factor

Quantitatively, there is a difference in the values of the pressure factor and the dynamic factor at the same place of the assembly and at the same Mach numbers. The dynamic factor, in contrast to the pressure factor, reflects qualitative dynamics of the absolute pressure behavior.

The dynamic factor, like the pressure factor makes it possible to determine whether the sought pressure is greater or less than the atmospheric pressure in the undisturbed flow. The difference is that the dynamic factor allows one to give such an estimate of its value without resort to ballistic calculations.

5. 3. Algorithm for the application of the operational procedure for determining pressure parameters in the transonic flight zone

Initial data for calculations include starting power-toweight ratio, distribution of the pressure factor, start altitude, air temperature at the time of launch, and altitude of the vertical section of the CR flight.

1. Analytical expression for the quasi-static component is obtained on the basis of combination of (9), (15) and (18) and is represented in the following form:

$$
P_{\mathrm{Q}-\mathrm{S}}=P_{\mathrm{SV}} P_{\mathrm{Q}-\mathrm{S}}^{*},
$$

where $P_{\mathrm{O}-\mathrm{S}}^{*}=e^{-\mathrm{B}\left(d_{1} M+d_{2} M^{2}\right)}$ is coefficient of quasi-static pressure (Table 3); $P_{\mathrm{SV}}=P_{0} e^{-\mathrm{\beta}\left(h_{S}+h_{\mathrm{V}}+\Delta h_{\text {remp }}(T)\right)}$ is the pressure at the CR flight altitude.

Dependence of the gradient of quasi-static component on the Mach number has the following form:

$$
P_{\mathrm{Q}-\mathrm{S}} / d M=P_{\mathrm{SV}} d P_{\mathrm{Q}-\mathrm{S}}^{*} / d M,
$$

where $d P_{\mathrm{Q}-\mathrm{S}}^{*} / d M=-\beta\left(d_{1}+2 d_{2} M\right) e^{-\beta\left(d_{1} M+d_{2} M^{2}\right)}$.

Coefficients $d_{1}, d_{2}$ for $v_{S}=1.2$ are given in Table 4 .

Failure to take account the vertical flight section in the model of the start altitude at the standard air temperature during the start and at an approximate value $P_{S V}=$ $=P_{0}=101325 \approx 10^{5} \mathrm{~Pa}$ leads to an error not exceeding $10 \%$, and (18) has the following form:

$$
P_{Q-S}=P_{Q-S}^{*} 10^{5} .
$$

2. Determination of the dynamic factor is carried out according to formula (9).

3. Finding of the absolute pressure on the surface of the aerodynamic assembly has the following form:

$$
P_{T}=P_{Q-S} C_{D}
$$

4. The pressure gradient proceeding from the Mach number is determined from expression (20) and is represented in the form:

$$
d P_{T} / d M=P_{S V} d P_{\infty} / d M
$$

where

$$
d P_{\infty} / d M=C_{D} d P_{Q-S}^{*} / d M+P_{Q-S}^{*} d C_{D} / d M .
$$

Analysis showed that neglect of the first summand results in an error less than $5 \%$ and expression (23) takes the form:

$$
d P_{T} / d M=P_{S V} P_{Q-S}^{*} d C_{P} / d M .
$$

Simplicity and convenience of the method consist in its linear dependencies between dimensionless coefficients.

\section{4. Verification of the developed mathematical mod-} el and methodology

Telemetry data from the sensors of absolute pressure on the cylindrical surface of the Dnepr CR were selected for verification $[28,29]$. Comparison of the theoretical and experimental data is shown in Fig. 3.

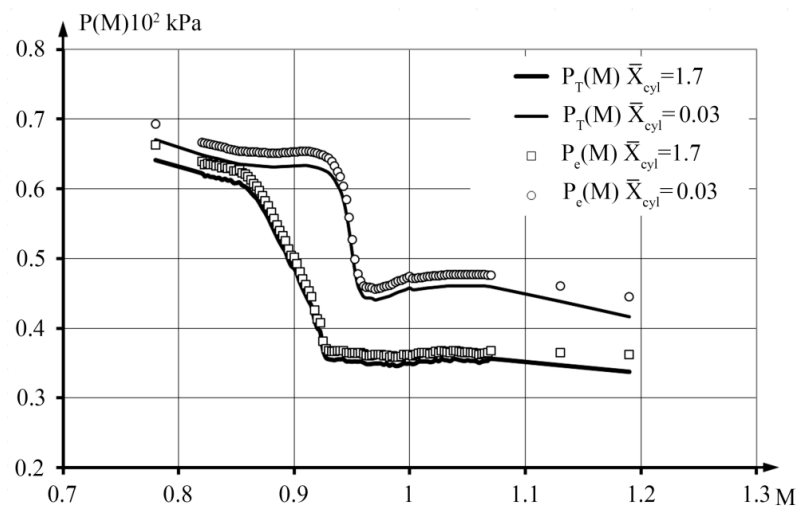

Fig. 3. Comparison of the theoretical and experimental pressure dependences

Qualitative match of theoretical and experimental data gives grounds to assert that the use of the dynamic factor is quite justified. Quantitative relationships determine values of the quasi-static component. Maximum discrepancy between theoretical and experimental data was observed not far from the Mach number $M=0.97$ for $\bar{X}_{c y l}=0.03$ and $M=1.13$ for $\bar{X}_{c y l}=1.7$ and did not exceed $5 \%$.

\section{Discussion and practical recommendations for} pre-selection of locations for placement of drainage devices

Application of this method can be considered as preparation of initial data for the study of pressure under the HF, i. e. in the SC location. Studies proceed in two directions: a decrease in the pressure gradient under the HF because it is a function of external pressure, and the dynamics of movement of air masses under the HF. From the analysis of dependence of pressure on the external HF surface it becomes possible to substantiate choice of location of the DD installation in accordance with the qualifying standards.

The first line of solving the problem of preliminary DD locations is based on the analysis of the CR trajectories. Based on the dynamic factor data presented in Fig. 3, possibility of reducing values of the pressure gradient under the HF was analyzed. For Dnepr CR, substitution of a steeper trajectory for a flat one was investigated in order that the CR passed the transonic zone at altitudes more than $2.5-4.7 \mathrm{~km}$. Analysis of the values showed that when the $\mathrm{CR}$ was moving along the trajectory with $v_{S}=2.1$, the maximum pressure gradient on the outer surface of the HF was 1.74 times higher for $\bar{X}_{c y l}=0.03$. For $\bar{X}_{c y l}=1.7$, pressure on the outer HF surface was 1.77 times higher compared with the gradient for the CR moving with $v_{S}=1.2$. Analysis of the values has shown that when the $\mathrm{CR}$ was flying along the trajectory 
with $v_{S}=2.1$, the maximum pressure gradient on the outer surface of the HF was 1.74 times higher than for the CR flying with $v_{S}=1.2$, for $\bar{X}_{c y l}=0.03$. The pressure gradient for the dimensionless coordinate $\bar{X}_{c y l}=1.7$ was 1.77 times larger than the gradient of the CR flying with $v_{S}=1.2$.

The second study line concerns presence of two DD located at different distances along the cylinder length and pressure on the outer surface of the cylinder in the region of one DD is higher than pressure under the HF. At this moment, pressure in the location of other DD is lower than pressure under the HF. From a physical point of view, interaction between two DD located at different distances along the cylinder length occurs due to the presence of air masses under the HF. The value of pressure under the HF during passage of the transonic zone was between the two curves shown in Fig. 3. Pressure on the HF surface is higher than the pressure at $\bar{X}_{c y l}=0.03$, but lower than at $\bar{X}_{c y l}=1.7$. Depressurizing occurs (air masses are released from under the HF) in the region of $\bar{X}_{c y l}=0.03$ and intake of air masses under the HF takes place in the region of $\bar{X}_{c y l}=1.7$. Selection of DD characteristics ensures approximation of the pressure values under the HF to either the upper or the lower curve (curves). This changes relationships between the intake of air masses under the HF and their discharge from under the HF. Thus, it is possible either to increase or decrease values of the pressure gradient under the HF. There is an analogy with communicating vessels [30]. With this approach, value of the pressure gradient under the HF will be determined by two factors: the pressure difference in the DD locations and the DD characteristics. An estimate of the values of pressure difference on the outer surface of the cylinder can be given on the basis of the dynamic factor values presented in Fig. 3 (see dependence of the dynamic factor). With this approach, it becomes possible to select another DD pair located on other $\bar{X}_{\text {Cen }}$ coordinates. There are possible variants of using more than two DD to optimize pressure parameters under the HF.

\section{Conclusions}

1. Pressure dependence on the pressure factor was analyzed. Dependence of pressure determination on size parameters was shown. A new form of representation of pressure vs. the pressure factor was proposed. The innovation made it possible to express dependence of pressure on dimensionless parameters and represent them in the form of two components: quasi=static and dynamic one.

2. The first (quasi-static) component was represented not only as a function of the flight time but also as a function of the Mach number. Studies were carried out for two extreme (minimum and maximum) values of the initial power-to-weight ratio. The second component (the dynamic factor) reflects features of flow around the cone-cylinder assembly at the transonic flight section. It depends on three variables: the taper angle, the longitudinal coordinate and the Mach number.

3. The mathematical model of calculating pressure and its gradient was developed for two extreme powerto-weight ratios. Main factors affecting parameters of the transonic zone were taken into account in the model development. These factors include altitude of the start point, temperature of the start environment, pitch turn angle, the drag coefficient and the power-to-weight ratio. An algorithm for calculating the pressure and its gradient was worked out and presented.

4. Comparison of theoretical and experimental data depending on the Mach number and its gradient showed qualitative coincidences. In quantitative terms, the discrepancy between theoretical and experimental data did not exceed $5 \%$.

5. Two lines of minimizing the gradient of the total pressure on the outer HF surface and, as a consequence, under the HF were proposed. The first line is passage of the transonic zone at relatively high altitudes in the earth's troposphere and launch of the CR taking into account increase in the CR launch altitude and at elevated temperatures of the launching environment. The second line of study is the use of not just one but simultaneously several DD located at different distances along the cylindrical part of the assembly. Due to the analogy with communicating vessels, the ratio between the volumes of intake and removal of air masses from under the HF varies with variation of the ratio of the DD characteristics.

References

1. Francisco, J. T. NASA space vehicle design criteria. Compartment venting [Text] / J. T. Francisco // NASA SP-8060. - NASA, 1970. $-31 \mathrm{p}$.

2. Atlas Launch System Mission Planner's Guide, Atlas V Addendum [Text]. - International Launch Services, 1999. - 80 p.

3. Atlas V Launch Services User's Guide [Text]. - United Launch Alliance, 2010. - 420 p.

4. Spacex [Electronic resource]. - Available at: http://www.spacex.com/sites/spacex/files/falcon_9_users_guide_rev_2.0.pdf

5. Scialdone, J. J. Spacecraft compartment venting [Electronic resource] / J. J. Scialdone. - NASA. - Available at: https://ntrs.nasa. gov/archive/nasa/casi.ntrs.nasa.gov/19980236692.pdf

6. Scialdone, J. J. Preventing Damaging Pressure Gradients at the Walls of an Inflatable Space System [Electronic resource] / J. J. Scialdone. - NASA. - Available at: https://ntrs.nasa.gov/search.jsp?R=20000070465

7. Timoshenko, V. I. Matematicheskaya model' gazodinamicheskih protsessov v sisteme gidravlicheski svyazannyh emkostey [Text] / V. I. Timoshenko, Yu. V. Knyshenko, V. I. Degtyarenko // Tekhnicheskaya mekhanika. - 1993. - Issue 5. - P. 3-9.

8. Degtyarenko, V. I. Opredelenie parametrov vozduha v otseke rakety na aktivnom uchastke poleta [Text] / V. I. Degtyarenko // Tekhnicheskaya mekhanika. - 1999. - Issue 1. - P. 17-22.

9. Timoshenko, V. I. Problems of thermostatic control and spacecraft safety at the pre-launch period and during orbital injection [Text] / V. I. Timoshenko, A. V. Agarkov, Y. I. Moshnenko, V. N. Sirenko, Y. V. Knyshenko, Y. G. Lyashenko // Space Science and Technology. - 1999. - Vol. 5, Issue 5-6. - P. 56-64. doi: 10.15407/knit1999.05.056

10. Im, E. Prospects of Large Deployable Reflector Antennas for A New Generation of Geostationary Doppler Weather Radar Satellites [Text] / E. Im, M. Thomson, H. Fang, J. Pearson, J. Moore, J. Lin // AIAA SPACE 2007 Conference \& Exposition. - 2007. doi: 10.2514/6.2007-9917 
11. Hill, J. Deployment of Inflatable Space Habitat Models [Text] / J. Hill, J. Jacob // 48th AIAA Aerospace Sciences Meeting Including the New Horizons Forum and Aerospace Exposition. - 2010. doi: 10.2514/6.2010-793

12. Shalabaeva, Z. A. Istoriya metodiki rascheta drenirovaniya «suhih» otsekov raket-nositeley [Text] / Z. A. Shalabaeva, P. V. Il'enko, V. F. Yatsuk, P. V. Semenenko // Materialy VIII naukovykh chytan «Dniprovska orbita». - Dnipropetrovsk, 2013. - P. 91-95.

13. Mehta, R. C. Quasi-One-Dimensional Numerical Analysis of Payload Venting of Satellite Launch Vehicle [Text] / R. C. Mehta // Journal of Spacecraft and Rockets. - 2008. - Vol. 45, Issue 2. - P. 412-415. doi: 10.2514/1.33673

14. Dykhuizen, R. C. Depressurization solutions of vented enclosures during launch [Text] / R. C. Dykhuizen, W. Gill, L. A. Bruskas // CEAS Space Journal. - 2011. - Vol. 3, Issue 1-2. - P. 7-12. doi: 10.1007/s12567-011-0022-x

15. Martin, P. J. Performing a Launch Depressurization Test on an Inflatable Space Habitat [Electronic resource] / P. J. Martin, P. Van Velzer. - California Institute of Technology, 2014. - Available at: https://trs.jpl.nasa.gov/bitstream/ handle/2014/45653/14-4003_A1b.pdf?sequence=1

16. Mehta, R. C. Aerodynamic Design of Payload Fairing of Satellite Launch Vehicle [Text] / R. C. Mehta // International Review of Aerospace Engineering (IREASE). - 2015. - Vol. 8, Issue 5. - P. 167. doi: 10.15866/irease.v8i5.8000

17. Benavente, F. M. B. Thermodynamic Study of Compartment Venting [Electronic resource] / F. M. B. Benavente // Avaialable at: https://fenix.tecnico.ulisboa.pt/downloadFile/1126295043835047/resumo.pdf

18. Woronowicz, M. S. On small disturbance ascent vent behavior [Text] / M. S. Woronowicz // 2012 in Optical System Contamination: Effects, Measurements, and Control 2012. - 2012. doi: 10.1117/12.946557

19. Smith, R. Compartment Venting on the Orion Crew Module During Atmospheric Re-entry [Text] / R. Smith // 49th AIAA Aerospace Sciences Meeting including the New Horizons Forum and Aerospace Exposition. - 2011. doi: 10.2514/6.2011-427

20. Il'enko, P. V. Obespechenie zadannoy skorosti spada davleniya v zone kosmicheskogo apparata rakety-nositelya «Dnepr» [Text]/ P. V. Il'enko, L. G. Chigrinets, P. V. Semenenko, T. V. Korol' // Kosmicheskaya tekhnika. Raketnoe vooruzhenie. - 2015. - Issue 1. P. 34-38.

21. Kashanov, A. E. Otsenka tekhnicheskih riskov pri puske rakety-nositelya «Dnepr» [Text] / A. E. Kashanov, A. V. Degtyarev, E. G. Gladkiy, E. Yu. Baranov // Aviatsionno-kosmicheskaya tekhnika i tekhnologiya. - 2012. - Issue 5. - P. 113-118.

22. Dehtiarenko, V. I. Perekhidni hazodynamichni pry vytikanni z yemnostei ta yikh modeliuvannia [Text]: avtoref. dys. ... kand. tekhn. nauk / V. I. Dehtiarenko. - Kharkiv, 2005. - 20 p.

23. Golubev, A. G. Aerodinamika [Text]: ucheb. pos. / A. G. Golubev, V. T. Kalugin, A. Yu. Lutsenko, V. O. Moskalenko, E. G. Stolyarova, A. I. Hlupnov, P. A. Chernuha. - Moscow: MGU, 2010. - 678 p.

24. GOST 4401-74. Tablitsy standartnoy atmosfery [Text]. - Moscow, 1974. -96 p.

25. Kompaniets, E. P. Ballisticheskoe obespechenie puskov raket-nositeley [Text]: monografiya / E. P. Kompaniets, N. M. Dron', V. E. Belozerov. - Dnepropetrovsk: izd-vo DNU, 2010. - 468 p.

26. Davydov, S. A. Issledovanie zavisimosti parametrov transzvukovoy zony poleta rakety-nositelya ot temperatury okruzhayushchey sredy starta [Text] / S. A. Davydov, P. V. Semenenko // Systemne proektuvannia ta analiz kharakterystyk aerokosmichnoi tekhniky. - 2013. - Vol. 16. - P. 30-46.

27. Semenenko, V. P. Protyazhennost' transzvukovoy zony poleta rakety-nositelya i vremya ee prohozhdeniya [Text] / V. P. Semenenko, P. V. Semenenko // Systemne proektuvannia ta analiz kharakterystyk aerokosmichnoi tekhniky. - 2013. - Vol. 15. - P. 92-100.

28. Itogovyy otchet po rezul'tatam puska RN «Dnepr-Vostok» [Text] / GP «KB «Yuzhnoe». - Dnepropetrovsk, 2005. - 156 p.

29. Itogoviy otchet po rezul'tatam podgotovki i provedeniya puska RN «Dnepr-1»s KA TerraSar-X [Text] / GP «KB «Yuzhnoe». Dnepropetrovsk, 2007. - 130 p.

30. Semenenko, V. P. The investigation of pressure gradients in a nonhermetic vessel [Text] / V. P. Semenenko // Machines, Technologies, Materials. - 2013. - Issue 6. - P. 18-20. 